\title{
Intelectuais e statemakers: Oliveira Vianna, Evaristo de Moraes Filho e a ação coletiva no Brasil
}

\section{Intellectuals and statemakers: Oliveira Vianna, Evaristo de Moraes Filho, and collective action in Brazil} Antônio da Silveira Brasil Jr.

Todo homem de Estado, na sociedade moderna, é mais ou menos um sociólogo Cândido Mota Filho, Alberto Torres e o tema de nossa geração (1933)

Em meados dos anos 1930, o recém-criado Ministério do Trabalho, Indústria e Comércio (MTIC) abrigaria em seus quadros dois intelectuais que podem ser considerados como pertencentes a campos políticos opostos: Francisco José de Oliveira Vianna (1883-1951)e Evaristo de Moraes Filho(1914-). O primei-

\footnotetext{
Antônio da Silveira Brasil é doutorando em Sociologia pelo Programa de Pós-Graduação em Antropologia e Sociologia (PPGSA) da Universidade Federal do Rio de Janeiro, Rio de Janeiro, Brasil (antoniobrasiljr@ gmail.com).

Artigo recebido em 30 de junho de 2010 e aprovado para publicação em 10 de setembro de 2010.
}

Est. Hist., Rio de Faneiro, vol. 23, $n^{o}$ 46, p. 301-320, julho-dezembro de 2010. 
ro, já consagrado ensaísta neste momento, atuou por oito anos como consultor jurídico do MTIC, e, na ausência de um código legal estabelecido, terminou por legislar (através de seus pareceres) sobre quase toda a matéria trabalhista e sindical entre 1932 e 1940, legando ainda vasta jurisprudência que seria incorporada pouco tempo depois na Consolidação das Leis do Trabalho (CLT). Em sua prática burocrática, mobilizou recorrentemente suas formulações a respeito do "insolidarismo" que marcaria a sociedade brasileira, tal como formulado desde Populações meridionais do Brasil (1920), utilizando-as como peças de persuasão para a implementação de um padrão autoritário de regulação da ação coletiva sindical.

Moraes Filho, por sua vez, após trabalhar durante sete anos como subordinado de Vianna - ainda muito jovem, secretariou as comissões mistas de conciliação do MTIC entre 1933 e 1941 -, assumiu o cargo de procurador da Justiça do Trabalho em 1941 e no ano seguinte passou a figurar como um dos assessores técnicos do ministro Marcondes Filho, o último do Estado Novo. Posteriormente, não só foi pioneiro no questionamento da tese do "insolidarismo", em $O$ problema do sindicato único no Brasil (1952), como também redigiu o anteprojeto do Código do Trabalho, feito a pedido do governo de João Goulart, que visava a substituir a CLT e a eliminar vários de seus dispositivos autoritários, o que não chegou a se concretizar.

Ainda que sob motivações e atribuindo sentidos muito distintos às suas atuações burocráticas, ambos se vincularam de modo central a este capítulo particular de construção do Estado-nação no Brasil: com a criação do MTIC, o que antes era, em larga medida, definido pelas demonstrações de força das classes sociais no mercado passa a ser arbitrado no interior do Estado, representando uma considerável inflexão histórica nas relações entre Estado e sociedade (Werneck Vianna, 1999). Apesar de terem compartilhado o ambiente do MTIC, sustentaram posições divergentes tanto no que diz respeito à dinâmica da sociedade brasileira quanto em seus projetos institucionais de intervenção sobre ela. Neste artigo, pretendo elaborar um possível marco comparativo entre estas diferentes posições no duplo nível em que elas se apresentam: no plano da análise sociológica e no plano da construção jurídico-institucional.

A participação de intelectuais no interior do Estado - ou ainda, a adesão dos homens de ideias ao "projeto" do Estado-nação - tem sido matéria de ampla reflexão na sociologia brasileira contemporânea. Em grande medida, como indicou Botelho (2005: 45), a bibliografia referida ao tema se polariza entre uma abordagem que vê esta relação sob o prisma da "cooptação" (Miceli, 2001), e uma outra, centrada na ideia da conversão dos intelectuais à ação política propriamente dita (Pécaut, 1990). A primeira localiza sobretudo o interesse dos intelectuais, travejamentos de classe incluídos, na ocupação dos novos cargos disponibilizados pela expansão da burocracia estatal; a segunda identifica uma certa 
permanência na auto-representação dos intelectuais como portadores de uma missão nacional, situando-se "acima do social". Neste trabalho, proponho uma leitura alternativa à ideia de "cooptação" ou de "missão" como forma de garantir a inteligibilidade sociológica da participação destes intelectuais na máquina estatal: interessa-me menos a natureza da relação travada entre estes intelectuais e o Estado, questão que vem polarizando a bibliografia, e mais a atuação deles como statemakers, isto é, como agentes empenhados na implementação, sempre tensa e conflituosa, de certas estruturas de regulação estatal da vida coletiva.

Cabe agregar, contudo, que tanto Vianna quanto Moraes Filho destacam-se como statemakers de um tipo especial, e justamente daí advém a sua utilidade heurística: eles não só se empenharam na criação de desenhos institucionais no campo do Direito do Trabalho, mas também encetaram reflexões, hoje consideradas clássicas, sobre a sociedade brasileira. Embora a atuação do Ministério estivesse limitada inicialmente às cidades, o contato estreito, a partir daí, com os atores coletivos mais densos do período - os sindicatos patronais e de trabalhadores urbanos -, propiciava sem dúvida um campo privilegiado de observação do movimento da sociedade como um todo, seja para forjar novas perspectivas explicativas, seja para corroborar antigas formulações.

No plano metodológico, não pretendo considerar essa dimensão eminentemente prática (mas reflexiva) de suas atividades como um elemento "externo" às suas elaborações intelectuais. Noutras palavras, não procurarei lidar com a participação intensa de Oliveira Vianna e de Moraes Filho no interior do Estado como uma espécie de constrangimento que se daria para além da atividade intelectual propriamente dita. Tal visão "externa" geralmente associa a proximidade com o Estado como uma perda de autonomia e, no limite, como um déficit cognitivo, dadas as urgências da política e suas racionalizações. Minha tentativa aqui é propor uma visão não-disjuntiva entre textos, trajetória e contexto social mais amplo (Botelho, 2005), buscando captar, no próprio princípio de composição dos seus textos, o equacionamento das tensões entre estas dimensões.

Assim, creio poder avançar a hipótese de que, para Vianna e Moraes Filho, a leitura da realidade social e a análise das instituições não se separam, mas antes se articulam internamente ao argumento. Enxergam, portanto, o processo social desde a socialização dos agentes até a institucionalização dos direitos, isto é, trazem a relação entre sociedade e Estado, com a qual lidam em suas práticas burocráticas, para o interior mesmo de suas reflexões. Logo, podemos alcançar um critério alternativo para a avaliação de suas obras, sem projetar retrospectivamente as expectativas da "autonomia" - sempre relativas, aliás - da ciência social em relação ao campo do poder. Ainda, podemos colocar em perspectiva o sentido geral do processo de profissionalização das ciências sociais no Brasil, que tendeu a separar jus- 
tamente a análise da socialização do mundo das instituições, a reflexão sociológica do conhecimento jurídico, este último mal-visto como ranço do bacharelismo anterior. Esta ressalva metodológica faz-se necessária porque o material a ser mobilizado aqui é de natureza eminentemente textual (livros, projetos, códigos etc.), ainda que eventualmente certos elementos de natureza histórica possam ser mobilizados em apoio à argumentação. Nesse sentido, o meu objetivo não é reconstituir tout court a atuação de Vianna e de Moraes Filho no âmbito do MTIC, tampouco avançar no esclarecimento sociológico do corporativismo estatal ou da ação sindical no Brasil, mas indagar em que medida as suas atividades como statemakers ensejaram formas de cognição específicas da realidade social.

Este artigo está organizado em três partes. Na primeira, reconstituo o debate travado por Evaristo de Moraes Filho em torno das proposições de Oliveira Vianna a respeito do "insolidarismo", isto é, da ideia de que haveria uma debilidade crônica nas formas de ação coletiva no Brasil; na segunda, trago à tona os diferentes desenhos institucionais desenvolvidos pelos autores com o intuito de fortalecer as instâncias associativas, selecionando para exame mais detido a questão da autonomia sindical; por fim, procuro caracterizar, na outra ponta de minha hipótese, em que sentido a marca do statemaker se faz presente mesmo em reflexões posteriores às suas passagens pelo Estado.

\section{O rural e o urbano: a fraqueza e a força da ação coletiva}

As formulações presentes em Populações meridionais do Brasil (1920), de Oliveira Vianna, e em O problema do sindicato único (1952), de Evaristo de Moraes Filho, iluminam facetas muito diferentes da sociedade brasileira. O livro de 1920, como seria comum ao ensaísmo das décadas de 1920-40, volta-se às raízes agrárias da formação da sociedade que aqui se forjou, destacando a dimensão de processo inscrita no presente vivido (Cândido, 2006: 235). Já o livro de 1952, originalmente uma tese universitária, ${ }^{1}$ circunscreve-se basicamente ao período republicano, sendo, como adverte o próprio autor, um estudo "de ordem sistemática e não de natureza histórica" (Moraes Filho, 1978: 182). Tais recortes temporais têm consequências para uma questão que, a meu ver, distingue os dois autores já de saída: enquanto Vianna elabora uma sociologia do mundo rural brasileiro, lendo a partir daí a dinâmica da sociedade como um todo, Moraes Filho concentra-se quase que exclusivamente na capacidade associativa dos grupos de trabalhadores urbanos, sobretudo no século XX. Não que o mundo urbano esteja ausente das formulações de Vianna, nem que o peso da formação histórica da sociedade brasileira seja descartado por Moraes Filho. Os dois autores vão buscar estas conexões, muito embora o façam de maneira problemática, como mostrarei mais à frente. 
Em Populações meridionais do Brasil: populações rurais do centro-sul, o argumento de Vianna concentra-se na análise das formas sociais assumidas pela propriedade fundiária desde os inícios da colonização. Seus traços mais marcantes seriam, por um lado, a "desmedida amplitude" dos domínios rurais, e por outro, o seu caráter "autárquico". O impacto da independência econômica dos latifúndios seria de tal ordem que chegaria a produzir uma "ação poderosamente simplificadora sobre toda a estrutura das nossas populações rurais" (Vianna, 2002: 1021). Ação com as consequências mais decisivas, que se traduziriam na pouca importância assumida pelo comércio, pela indústria e pelos centros urbanos, todos inviabilizados pelo "centripetismo absorvente" do grande domínio rural. Por essa razão, no que diz respeito à formação da sociedade e sua estruturação, diz o autor: "só os grandes senhorios rurais existem. Fora deles, tudo é rudimentar, informe, fragmentário. São os grandes domínios como que focos solares: vilas, indústrias, comércios, tudo se ofusca diante de sua claridade poderosa" (Vianna, 2002: 1022-1023).

Assim, dada esta estrutura social "simplificada" pelo grande domínio rural como centro de gravitação do mundo colonial, também a esfera da sociabilidade sentiria a sua influência absorvente. Sua expressão-síntese seria o "clã rural", grupo social que se constituiu, "desde o primeiro século, nos campos, em torno e sob a direção suprema do grande proprietário de terras" (Vianna, 2002: 1035). Toda a população rural, "de alto a baixo, está sujeita ao mesmo regime, toda ela está agrupada em torno dos chefes territoriais" (Vianna, 2002: 1035). Sua força seria tamanha que até mesmo a extensa camada de homens livres e pobres - a "plebe rural", nos termos do autor, e para quem a ligação econômica com os fazendeiros seria tão frágil quanto instável, porquanto a escravidão os tornava desnecessários à produção agro-exportadora -, estaria reunida sob a dominação de um senhor de terras, de um "chefe de clã".

Para Vianna, o "clã rural" tiraria sua força da necessidade de proteção do "baixo campônio" contra a arbitrariedade dos mecanismos de coerção estatal. Isso porque também as instituições públicas cairiam na órbita dos senhores territoriais, os quais, sem ter quem lhes contestasse efetivamente o poder, usavam-nas em prol de seus interesses - mecanismo por ele designado "anarquia branca". Nessas condições - e o ensaio dá como exemplos o caráter faccional da justiça, a arbitrariedade do recrutamento militar e a parcialidade das corporações municipais -, não restaria outra opção aos grupos sociais subalternos a não ser se refugiarem sob o "poder tutelar" dos clãs rurais, já que até o direito à propriedade lhes estava vedado.

Assim, "depois da solidariedade parental", acrescenta Vianna, seria o "clã fazendeiro a única forma militante da solidariedade social em nosso povo" (Vianna, 2002: 1047). Gerando um "espírito de clã" que lhe seria correspondente, e que poderia inclusive sobreviver à crise destas bases sociais que lhe deram 
vida, o predomínio desta forma de solidariedade constituiria, para o autor, um dos principais problemas para a organização da sociedade brasileira, posto que redundaria na dificuldade ou mesmo impedimento de criação de instâncias de livre associação entre os indivíduos que visassem aos interesses públicos. ${ }^{2} \mathrm{Ou}-$ tras formas de solidariedade, inclusive aquelas que historicamente tinham sido a base social necessária para o assentamento eficiente da autoridade pública nas sociedades anglo-saxãs - na comparação recorrentemente feita pelo autor - não teriam se realizado: “os 'partidos', [...] os 'sindicatos', as 'associações' [...], a 'Nação' - são entre nós meras entidades artificiais e exógenas, sem realidade efetiva na psicologia subconsciente do povo" (Vianna, 2002: 1128). Em expressões que sintetizam o argumento do livro, arremata: "são escassíssimas as instituições de solidariedade social em nosso povo"; "aqui, o homem vive isolado dentro dos latifúndios ou do seu círculo familiar"; "a insolidariedade é completa" (Vianna, 2002: 1050-1051).

Moraes Filho, em O problema do sindicato único no Brasil: seus fundamentos sociológicos, começa a sua análise no ponto onde Vianna havia parado. Para este último, o período republicano, que não foi tratado em Populações, exigiria "um estudo à parte, minucioso, preciso, complexo", uma vez que, nele, "o nosso povo entra numa fase de desorganização profunda e geral, sem paralelo em toda a nossa história" (Vianna, 2002: 928). Numa direção contrária à de Vianna, Moraes Filho, ao inquirir sobre as tentativas de organização profissional no Brasil, dirá que é justamente com o fim do Império, quando avança com mais força a urbanização, que se dão os primeiros ensaios de estruturação social dos trabalhadores. Porque, antes, "numa sociedade escravocrata, toda ela baseada no trabalho servil, com a indústria ainda em seus primeiros ensaios, [...] com escassa densidade populacional, não era possível encontrar clima propício à organização coletiva do trabalho" (Moraes Filho, 1978: 182).

A reconstituição da movimentação operária na Primeira República feita por Moraes Filho baseia-se numa série de materiais empírico-documentais. Recupera discursos parlamentares, atas de congressos operários, pronunciamentos de intelectuais ligados à classe operária, notícias da imprensa a respeito de greves ou paralisações, legislações trabalhistas etc. Chama a atenção, por exemplo, para a existência de um Congresso Operário realizado no ano de 1912 para o qual "compareceram ao todo, entre federações, uniões, sindicatos, ligas e centros, cinquenta e sete entidades" (Moraes Filho, 1978: 195). Outro episódio marcante seriam as greves de 1919, que transcorreram "nos centros principais do Brasil: Rio, S. Paulo, Recife e Salvador" (Moraes Filho, 1978: 199). Nesta última cidade, diz que "alastrou-se o movimento por toda a Capital do Estado e inclusive em algumas localidades do interior. Deu-se fechamento total do comércio. Na indústria, não foi menor a paralisação" (Moraes Filho, 1978: 199). O mesmo teria ocorrido 
na capital da República: “Toda a vida industrial e comercial do Rio de Janeiro viveu um período de iguais movimentos grevistas. Os jornais dos meses de junho e julho de 1919 estão cheios de notícias de paradas de trabalho" (Moraes Filho, 1978: 203).

Através desses elementos, o autor quer mostrar "o quanto há de falso o pretender-se fazer da classe operária o espectador inerme dos fatos que lhe diziam respeito", sendo, para ele, uma "afirmativa sem fundamento a declaração de que estes movimentos nunca impressionaram o governo e as classes patronais" (Moraes Filho, 1978: 192). Criticando, pois, a concepção de que a legislação trabalhista pós-1930 teria sido uma outorga do governo varguista, e não uma conquista proveniente do acúmulo das lutas operárias dos decênios anteriores, assinala:

Não houve outorga nenhuma, como quem dá esmola a um débil mental. As massas operárias lutaram durante um triênio - e ainda lutam hoje e continuarão a lutar - pelo advento de leis que lhes melhorassem as condições de vida. Houve greves, lutas, sangue, desespero, prisões, mortes. Como falar-se em pobre diabos, sem líderes, sem ideias, sem aspirações, que receberam tudo que se lhes queria dar como favores espontâneos e unilaterais? (Moraes Filho, 1978: 214).

A argumentação de Moraes Filho não se resume, no entanto, a uma simples descrição dos diferentes episódios da organização dos trabalhadores na Primeira República. Na primeira parte de $O$ problema do sindicato único no Brasil, além de elaborar uma discussão bastante abrangente sobre a noção de "grupo social", também examina as consequências do advento do mundo urbano-industrial no plano das sociabilidades. Entre outras dimensões, aponta como os efeitos da produção industrial em larga escala contribuíram para transformar em "grupo social" os indivíduos que, na vida econômica moderna, exercem a mesma profissão: "devido às mesmas condições de vida, aos mesmos expedientes técnicos de exercício ocupacional, que determinam geralmente o mesmo nível de vida [...], mantém-se no seio de qualquer categoria profissional um sentimento bem vivo de comunhão de interesses" (Moraes Filho, 1978: 59). Nessa direção, a passagem do grupo profissional à forma de ação coletiva que lhe é peculiar - o sindicato - seria "espontânea": "assim como é natural a existência desse grupo profissional, também o é a consciência de que aproximados, coordenados, poderão todos os seus membros defender melhor os seus interesses" (Moraes Filho, 1978: 60). Ora, uma vez que a sociedade brasileira também se urbanizava e assistia ao começo de sua industrialização, seria igualmente esperado que os indivíduos assim concentrados na produção fabril cedo ou tarde se mobilizassem coletiva- 
mente. Daí se explicaria sociologicamente por que houvera a intensa agitação operária reconstituída pelo autor.

À primeira vista, portanto, a abordagem de Moraes Filho, ao concentrar-se no nível dos grupos sociais - neste caso, das associações operárias - e na dimensão sincrônica, não dá continuidade à tese do "insolidarismo" que havia sido tornada clássica por Vianna. Contudo, na última (e curta) seção do livro, intitulada justamente "O insolidarismo social brasileiro e o sindicato único", retoma as formulações de alguns intérpretes da formação histórica da sociedade brasileira - como Capistrano de Abreu, Sérgio Buarque, Gilberto Freyre, Alberto Torres e o próprio Oliveira Vianna - e termina por reiterar a própria visão que o andamento geral de O Problema do sindicato único no Brasil pretendia colocar em suspenso. A recuperação da perspectiva diacrônica torna o argumento do autor ambíguo, como na seguinte passagem: "nunca vivemos mergulhados profundamente nessas instituições de solidariedade social. Tudo aqui é fugaz e superficial, nasce com muito calor e alarido, e morre com não menores esquecimento e abandono" (Moraes Filho, 1978: 314). Ao final do livro, tem-se a impressão de que o autor não levou às últimas consequências a sua perspectiva não-cética das possibilidades de ação coletiva na sociedade brasileira.

No entanto, pode-se dizer que é igualmente problemática a leitura do mundo rural feita por Oliveira Vianna, principalmente quando se leva em conta que é a partir dela que o futuro consultor jurídico do MTIC buscará legitimar suas decisões legais, a despeito de lidar praticamente com atores coletivos urbanos. No prefácio de Populações, Vianna explica por que não consideraria os "tipos urbanos", apesar de reconhecer que "agora" - em 1918, quando escreve este prefácio estes "começam a ter uma caracterização especial" (Vianna, 2002: 926). Para ele, os homens das cidades não passariam, "depois de bem analisados, de reflexos ou variantes do meio rural, a que pertencem", sendo a sua "posição secundária - porque, na realidade, o tipo rural, que os defronta, praticamente os subordina" (Vianna, 2002: 926). Apesar de se encontrar estreitamente vinculado, através de sua prática burocrática, ao que havia de mais dinâmico nas sociabilidades urbanas emergentes, Oliveira Vianna nunca chegou a pôr em questão o diagnóstico elaborado em seu livro de estréia, quer dizer, jamais questionou o poder plasmador da solidariedade - ou melhor, da "insolidariedade" - engendrada pelo latifúndio.

\section{A codificação da ação coletiva: tutela ou autonomia}

Essas diferentes leituras da sociedade brasileira foram acionadas pelos autores em suas propostas de codificação legal da ação coletiva no âmbito sindical. Tanto Vianna quanto Moraes Filho pretenderam, através de instrumentos 
jurídicos, "superar" as debilidades associativas por ele identificadas, ainda que o último tenha atribuído um grau muito maior de capacidade de ação aos atores coletivos urbanos. Essas diferenças, não obstante os pontos de contato assinalados acima, informarão os distintos graus de autonomia legal presentes nos dispositivos normativos elaborados pelos autores.

Oliveira Vianna, em sua longa atuação na consultoria jurídica do MTIC, ${ }^{3}$ empregou frequentemente a tese do "insolidarismo", presente em Populações, para defender a fórmula do controle dos sindicatos pelo Estado. No prefácio a Problemas de direito sindical (1943), que reúne em livro os artigos mais polêmicos escritos de sua passagem pelo Estado, o autor chega a esta fórmula bastante condensada de articulação entre "prognóstico" e "diagnóstico":

O grande movimento no sentido da sindicalização, que agora se inicia em nosso país, é assim o primeiro passo para a organização social do nosso povo [...]. Num povo como o nosso, de formação anti-urbana, [...] o sindicalismo representa o papel de um agente corretivo ou retificador: é, realmente, o processo mais eficaz, rápido e seguro para a intensificação entre nós dessas formas de solidariedade social e de "consciência de grupo". Formas que o brasileiro não pôde constituir e cristalizar durante os quatro séculos de sua história social (Vianna, 1943: vii).

Cumpre ressaltar que a adoção desta proposta sindicalista de superação do "insolidarismo" não se apresentava no horizonte de Populações. No livro de 1920, o autor se limita a uma defesa do Estado centralizado, na expectativa de que este pudesse desenvolver uma "consciência comum a uma vasta massa social ainda em estado ganglionar", isto é, que pudesse realizar o "milagre de dar a essa nacionalidade em formação uma subconsciência jurídica, criando-lhe a medula da legalidade" (Vianna, 2002: 1167). Essa profissão de fé na ação do Estado ganhará contornos mais concretos somente nos anos 1930, quando, após algumas hesitações, ${ }^{4}$ Vianna se decide por fazer do sindicato tutelado o instrumento por excelência de combate ao "espírito de clã", funcionando como um elemento de mediação entre as demandas de centralização da autoridade e a dinâmica social mais ampla.

Os sindicatos profissionais seriam, de acordo com Vianna, a melhor "técnica" para criar - é importante frisar este ponto - instâncias de solidariedade. Para ele, "as nossas classes ou categorias profissionais, nas cidades e nos campos, não puderam adquirir, senão em raríssimos setores, densidade, espessura, consciência, organização" (Vianna, 1943: vi). O que estaria faltando para a apari- 
ção do fenômeno associativo seria "um estímulo externo", uma "corrente de excitação que as condições específicas de nossa formação social e histórica não lhes puderam fornecer" (Vianna, 1943: vi). Este estímulo, segundo Vianna, só poderia vir do Estado, a quem caberia também uma vigilância estrita sobre a movimentação sindical. Não por acaso, ele estabelece na Lei Orgânica de Sindicalização (cuja comissão presidiu) como dever específico do sindicato "colaborar com os poderes públicos no sentido do desenvolvimento da solidariedade das classes produtoras e da harmonização dos seus interesses" (Vianna, 1943: 215).

No fundo, a obrigatoriedade da "colaboração" também visaria ao combate dos "excessos" da ação coletiva sindical - quando esta fosse usada para fins políticos ou extra-profissionais, por exemplo-, dizendo explicitamente que pretendia, com esta lei, "preservar a vida interna dos sindicatos da contaminação dos maus elementos sociais, das intervenções estranhas e corruptoras, das infiltrações de ideologias perturbadoras" (Vianna, 1943: 208). Restringindo, assim, a liberdade sindical apenas à dimensão individual - Vianna nunca chegou ao extremo de defender a sindicalização obrigatória -, os graus de controle estatal previstos são explicitados em seu mais alto grau:

Com a instituição deste registro [sindical], toda a vida das associações profissionais passará a gravitar em torno do Ministério do Trabalho: nele nascerão; como ele crescerão; ao lado dele se desenvolverão; nele se extinguirão. Pareceu à Comissão mais razoável [...] que as associações profissionais se viessem a constituir no Ministério que tem como finalidade suprema a proteção de todas as atividades trabalhadoras do país, do que fora dele, fora do alcance de sua assistência e tutela (Vianna, 1943: 209).

Embora reconheça que haja "excesso de estatismo" em sua orientação sindical, pondera que a sua ausência constituiria um dilema: "ou esse estatismo, ou então a volta fatal à estrutura coloidal, à gelatina da Constituição de 1891" (Vianna, 1943: 90-91). Como a sociedade brasileira seria, para Vianna, incapaz de se organizar autonomamente, o afrouxamento dos controles estatais apenas reforçaria as suas tendências fragmentadoras, dispersivas, clânicas - numa palavra, o "insolidarismo".

Dilema do qual, no entanto, pretende escapar Moraes Filho. Ainda que também assinale a existência de um "insolidarismo", não deixa de ressaltar igualmente a existência de um movimento espontâneo no interior da sociedade que lhe tornaria capaz de se auto-organizar, para além dos controles do Estado (Villas Bôas, 2005). Seu Anteprojeto de Código de Trabalho (1963), cujo fim era a 
substituição da Consolidação das Leis Trabalhistas (CLT), além de excluir a "obrigatoriedade" de colaboração do sindicato com o Estado, define-se amplamente pela liberdade sindical, inclusive regulamentando o direito à greve. Propõe ainda uma série de dispositivos novos, como os conselhos de fábrica, destinados a democratizar as relações de trabalho e a reduzir o que chama de "paternalismo estatal", que se manifestaria no excesso de controles por parte do governo. Em suas palavras:

Esse paternalismo se manifesta no excesso de regulamentação legislativa, tudo resolvido através de leis, de decretos ou de portarias [...]. Habituadas a tudo obterem do Estado, dificilmente procuram as classes produtoras, tanto de empregados como de empregadores, solucionar os seus conflitos de interesses através de medidas mais plásticas e concretas, como, por exemplo, com a constituição de conselhos de empresa e através da prática de convenções coletivas de trabalho. A legislação do trabalho brasileira é imposta de fora para dentro das empresas, heteronomamente, coercitivamente, sem o livre debate, e a aceitação autônoma das classes interessadas (Moraes Filho, 1963: 43-44).

Outro ponto sensível de sua defesa da autonomia sindical é a crítica ao imposto sindical, mecanismo de tributação defendido por Vianna e instituído, efetivamente, em 1942. Destinado a garantir um fluxo de rendas regular ao sindicato, com vistas a aparelhá-lo e torná-lo atraente aos trabalhadores, baseava-se no pagamento compulsório de um dia de trabalho, não importando se o trabalhador era sindicalizado ou não. Atentando para a inconstitucionalidade desta medida, já que implicava uma espécie de sindicalização obrigatória - "com o que possa haver de pior, só os ônus sem nenhuma vantagem" (Moraes Filho, 1963: 73) -, Moraes Filho chama também a atenção para os seus efeitos deletérios na ação coletiva:

O imposto sindical é o caldo de cultura dos falsos líderes sindicais. Com dinheiros alheios, locupletam-se os cofres dos sindicatos, tornando desnecessário qualquer esforço de conquista de prestígio, pelos dirigentes sindicais. Com dinheiro em caixa, não se aguilhoa o espírito na formação de verdadeiros líderes, de educação e elevação da classe, de aumento do patrimônio, de serviços sociais, em suma, de benemerência que recomendem um verdadeiro chefe par droit de conquête (Moraes Filho, 1963: 79). 
Contrário, pois, aos efeitos inibidores do imposto sindical para o estabelecimento de uma ação coletiva vigorosa, já que o mesmo ensejaria enrijecimento e cooptação das lideranças trabalhistas, afirma que "o verdadeiro movimento sindical é luta, reivindicação, risco". Ora, "como falar-se em sacrifício e desprendimento, com o cheque no guichet do Fundo Social Sindical? Sindicato é escola de energia" (Moraes Filho, 1963: 70). Observador privilegiado das repercussões da rotinização das estruturas corporativistas na prática sindical, com as quais lidava diariamente em seu trabalho como procurador, Moraes Filho as critica tanto pelo seu teor autoritário quanto pela sua ineficácia em resolver os problemas associativos no Brasil. "Deve o Estado deixar autonomamente a cargo das diversas associações os seus problemas específicos", pondera o autor, pois a "sua função precípua é de harmonizar o caráter funcional das diferentes organizações concretas da sociedade, mas não roubar-lhes o objeto próprio e inconfundível" (Moraes Filho, 1978: 127).

Se a história havia juntado estes dois intelectuais, ainda que temporariamente, no mesmo ambiente do MTIC, por outro, ela os separou quando se compara o destino reservado aos seus respectivos projetos institucionais. A atuação de Vianna na consultoria jurídica deixou marcas expressivas, como a lei de sindicalização, o projeto da Justiça do Trabalho, os pareceres técnicos - matéria-prima jurisprudencial, incorporada depois à CLT -, embora não tenha sido exitoso na sua disputa com os industriais paulistas, refratários aos controles estatais estipulados por Vianna à atuação de suas organizações de classe, como a Federação das Indústrias do Estado de São Paulo (FIESP). Nessa disputa, formou-se um grande debate nas páginas do fornal do Comércio entre Vianna e os representantes dos grupos industriais, vencido pelos últimos, que culminou inclusive com a saída do então consultor jurídico do Ministério. ${ }^{5}$ Moraes Filho, por outro lado, além de não ter visto o seu $\mathrm{O}$ Anteprojeto de Código de Trabalho ser implementado, assistiu ao novo reforço do controle do Estado sobre os órgãos sindicais durante o longo período da ditadura militar no pós-1964.

\section{Conservadorismo e utopia: as marcas do statemaker}

Comparando-se os textos de Oliveira Vianna antes e após a sua passagem pelo Estado, algumas diferenças saltam à vista. Apesar de deixar sua marca de statemaker em diversas leis, tanto o eclipse do Estado Novo quanto a resistência oferecida pelos grupos industriais parecem ter reforçado o seu ceticismo quanto à superação do "espírito de clã" e, consequentemente, do "insolidarismo" por ele gerado. 
Em Instituições políticas brasileiras (1949), um de seus últimos livros, parece não ser sem consequências a adoção da noção de "complexos culturais", especialmente para tratar do "espírito de clã". Com essa modificação, sugere-se que o mesmo não seria um fenômeno transitório, ao qual caberia ao Estado, com os seus controles, extirpar, uma vez que estes "complexos" tenderiam "à estabilidade e, portanto, a resistir às inovações” (Vianna, 1982: 713). A ação estatal poderia, quando muito, neutralizá-lo, jamais eliminá-los completamente: "não creio que possamos mover contra ele uma política de eliminação completa, de expurgo integral [...]. E não creio - porque acredito na vigorosa tenacidade deste nosso complexo político" (Vianna, 1982: 713).

Esse ceticismo quanto às possibilidades de remodelagem do social pelo Estado não significa, no entanto, nem descartá-lo, por um lado, nem deixar de defender a centralização do poder, por outro. Em Instituições, Oliveira Vianna defende ainda o uso da "técnica autoritária", exemplificando para tal o sucesso, do seu ponto de vista, da política de sindicalização urbana. Todos os casos de legislação eficiente, no Brasil, se caracterizariam pela "utilização direta ou indireta do princípio fundamental da técnica autoritária", isto é, pelo uso de "um modicum de coação" (Vianna, 1982: 711). A principal inflexão deste livro de 1949 parece residir no grau de eficácia da ação do Estado para reorientar a dinâmica social como um todo. Diz o autor que, mesmo com uma "política de neutralização, tanto quanto possível, dos efeitos do espírito de clã na nossa vida pública", isso se daria, "de certo, muito relativamente e assim mesmo em parte" (Vianna, 1982: 713). Afinal, o Estado autoritário, embora "armado de faculdades e poderes excepcionais que não possuía o Estado Liberal, pode muito, sem dúvida, mas não pode tudo" (Vianna, 1982: 703). A esperança de "superar" os problemas associativos, ao que parece, foi desfeita, já que o ator por excelência da mudança social, o Estado, parecia-lhe limitado para tais fins.

Além desse reajuste de expectativas em relação à eficácia do Estado, outro ponto de inflexão após a sua atuação pelo MTIC é sua análise das repercussões do capitalismo na sociedade brasileira. Se em Populações ele punha entre parênteses a experiência urbana - ou melhor, absorvia o "tipo urbano" no "tipo rural”, o que pressupunha, portanto, uma continuidade do "espírito de clã" para além das condições sociais que o geraram -, em História social da economia capitalista no Brasil (1987), seu último livro (publicado postumamente), ${ }^{6}$ a passagem para um tipo urbano-industrial de sociedade se coloca no centro de suas preocupações. Neste livro, há uma forte crítica ao que denomina de "supercapitalismo", para cuja caracterização recorre a Werner Sombart. Entendido como uma forma específica de mentalidade, Vianna o define de maneira bastante negativa: "concorrencismo frenético e agressivo", tendência "à conquista do poder político [...], à subordinação da força do mecanismo do Estado aos seus interesses", "en- 
focação obsidional da ideia de lucro, cegando no businessman outras preocupações éticas" (Vianna, 1987a: 46-47).]

Ainda que assinale que a propagação do "supercapitalismo" se fazia visível no Brasil, desacredita que o mesmo pudesse se generalizar para o conjunto da população. Talvez não seja por acaso, haja vista suas disputas com os industriais de São Paulo, que o autor concentre a sua área de influência exclusivamente neste estado, diferenciando inclusive a indústria paulista da carioca. "O industrialismo do Planalto", afirma, "difere sensivelmente do industrialismo do Litoral. $\mathrm{O}$ sistema industrial paulista se inclina visivelmente para as grandes empresas, ao contrário do carioca, que abre larga margem às empresas de tipo artesanal" (Vianna, 1987a: 233). Ao circunscrever, desse modo, o campo de influência mais marcante da mentalidade capitalista - ou "supercapitalista", com suas tonalidades negativas - a uma única região do país, Vianna pretende avançar a ideia de que transformação dos meios de vida acarretada pelo capital não significaria necessariamente uma adesão ao seu estilo de vida, que permaneceria em larga medida informado pela mentalidade rural. Segundo ele, "a generalização entre nós deste supercapitalismo sombartiano" estaria reservado apenas a "um futuro distante. Enquanto este futuro distante não nos chega", completa, "é certo que as nossas empresas industriais continuarão (salvo talvez na Paulicéia) a ser, ainda por muito tempo, o que até agora têm sido - bases de vivência dos seus proprietários, dirigidas do bom e tradicional modo pré-capitalista" (Vianna, 1987b: 62-63). Noutras palavras, apesar de trazer ao primeiro plano o mundo urbano-industrial emergente, Vianna apenas reforça, uma vez mais, o seu argumento de que este não seria capaz de reorientar os padrões seculares de conduta forjados nos "quatro séculos" de vida rural.

Em certo sentido, esse "espírito do pré-capitalismo" seria uma espécie de contra-face, agora positiva, do "espírito de clã", posto que ambos são frutos da sociabilidade gestada nos latifúndios rurais. Se este último é geralmente pintado por ele de maneira negativa, como "o mal que envenena a nossa existência" (Vianna, 1982: 713), o primeiro funcionaria como um esteio capaz de evitar a explosão dos conflitos que invariavelmente acompanhariam a marcha do capitalismo pelo mundo. Isso porque o "audacioso espírito de dominação, cupidez e violência", típico da mentalidade "supercapitalista", destoaria

profundamente daquela moderação, daquela pauta, daquela mediania, daquele desprendimento em questão de dinheiro, que constituíam outrora [...] e ainda constituem hoje, felizmente, na generalidade do país, os traços dominantes da mentalidade das nossas aristocracias agrárias e das nossas burguesias industriais e mercantis (Vianna, 1987b: 197). 
Se, antes, o "espírito de clã" era associado a tendências disruptivas, dispersivas e, no limite, conflituosas, na nova chave de leitura de Vianna, o "espírito do pré-capitalismo" representará o seu inverso, quer dizer, a possibilidade de uma passagem ao mundo urbano sem os conflitos que lhe seriam característicos. Neste sentido, não seria o Estado, com os seus controles, o único princípio capaz de ordenar a sociedade, mas a sua ação conjugada com "estas terras pacíficas e fartas do Pré-Capitalismo e do Paternalismo Industrial” (Vianna, 1987b: 123). Não desconsiderando os efeitos da Revolução de 1930, que contribuíram, afirma, para "atalhar os males desta brusca evolução supercapitalista da nossa estrutura econômica" (Vianna, 1987b: 123), o êxito da política varguista se explicaria justamente em função daqueles valores rurais, generalizados na sociedade brasileira. Numa passagem do livro, assinala que "os nossos próprios burgueses, que foram diretamente atingidos pela nova política social, procuraram realizar este pensamento do Estado, sem lhe opor nenhuma reação séria" (Vianna, 1987b: 126). No que se refere aos trabalhadores, diz que "ainda guarda[m] uma mentalidade pré-capitalista - e esta mentalidade é imprópria para a luta de classes e para a agitação" (Vianna, 1987b: 125). Se houve conflitos, ou foi decorrência da agressividade de alguns "supercapitalistas", ou resultado da "ação insidiosa de agentes estrangeiros que se infiltraram na massa brasileira, excitando-a e levando-a a atos contrários à sua habitual feição acomodatícia e resignada" (Vianna, 1987b: 125). Em suma, ao revalorizar positivamente os valores e as formas de sociabilidade gestadas na velha sociedade rural - antes vistas, ao menos em parte, em tons críticos -, Vianna parece reforçar ainda mais o seu conservadorismo.

No caso de Moraes Filho, as marcas do statemaker também se fazem presentes, porém em outro âmbito. Não modificando, no essencial, nem a sua leitura da sociedade, nem a sua defesa de uma maior autonomia à ação coletiva sindical, ${ }^{7}$ situam-se talvez no modo pelo qual reinterpretou alguns autores clássicos do pensamento social e político brasileiro, tratando de desembaraçar-se de alguns lugares-comuns. $\mathrm{O}$ autor tenciona pôr em suspenso a leitura - feita, entre outros, por Vianna - de que os liberais brasileiros seriam alheios às realidades específicas do país, e o faz através da seguinte estratégia: em vez de concentrar-se apenas em seus aspectos doutrinários, prefere antes pôr em evidência os diferentes projetos de intervenção na realidade por eles concebidos. Noutras palavras, interpreta-os também como statemakers.

Tal orientação encontra-se presente em As ideias fundamentais de Tavares Bastos (1978). Pode-se dizer que foi um livro inovador, tanto pelo método - compulsou manuscritos e outros materiais empírico-documentais que estavam disponíveis na Biblioteca Nacional -, quanto pela heterodoxia da sua posição: a interpretação de Moraes Filho pretendeu problematizar a concepção que reduzia Tavares Bastos à bandeira da descentralização político-administrativa, que seria vista 
como "a panacéia mágica para todos os males do Brasil" (Moraes Filho, 2001: 46). Isso porque, segundo Moraes Filho, ele era um "autêntico cientista social", isto é, "lançada a meta valorativa a ser atingida, entregava-se à sua demonstração com rigorismo e objetividade" Moraes Filho, 2001: 23). Além disso, afirma ser o publicista do Império não um liberal tout court, mas um "social-liberal", visto que, ao mesmo tempo em que criticava as medidas "rígidas, forçadas, que sufocavam ou impediam as livres manifestações da sociedade" (Moraes Filho, 2001: 29), defendia, quando necessário, a intervenção pragmática do Estado na vida social. No âmbito das questóes relacionadas à força de trabalho, por exemplo, Tavares Bastos já teria previsto os seguintes pontos de reforma: "duração do trabalho, proteção ao trabalho do menor, descanso semanal, regulação do contrato de parceria e da locação de serviços, nacionalização do trabalho, com proteção do trabalho nacional no comércio varejista, etc." (Moraes Filho, 2001: 38). Criticando, assim, a visão de Vianna de que Tavares Bastos seria um "idealista utópico", ele assinala:

Ao contrário do que afirma Oliveira Viana, não é entre os idealistas utópicos que deve ser classificado, e sim entre os idealistas orgânicos, sempre voltado para a realidade, atento, objetivo, observador. O próprio Oliveira Viana vai se socorrer dele, várias vezes, das suas opiniões, do seu testemunho, para bem caracterizar a sociedade imperial. Constitui uma contradição chamar alguém de sonhador, e depois servir-se de seus "sonhos" como testemunhos e documentos históricos de fonte primária (Moraes Filho, 2001: 28).

Uma proposta interpretativa semelhante também pode ser encontrada em Temas de liberalismo e federalismo no Brasil (1991), no qual recupera, entre outras questões, a pregação de Rui Barbosa a favor do "desenho industrial". Tomando para análise os pareceres de Rui Barbosa como relator da Comissão de Instrução Pública, já em fins do Império, Moraes Filho põe em destaque a sua proposta de fomentar o ensino das "artes práticas" como uma forma de "aparelhar o país para uma rápida e segura industrialização" (Moraes Filho, 1991: 82), já que, na sua interpretação, o publicista baiano não queria "só modernizar o seu país, como igualmente vê-lo realmente desenvolvido, com tecnologia própria e mão-de-obra qualificada" (Moraes Filho, 1991: 93). E acrescenta:

Mas não se pense que Rui vivia no mundo da lua, perdido e inebriado no meio das suas fontes bibliográficas. Com os pés na realidade, interessava-lhe a transformação do seu país [...] Toda essa sua in- 
sistência a favor do ensino e da máxima difusão do desenho tinha um objetivo prático, econômico, para a renovação da sociedade brasileira (Moraes Filho, 1991: 79).

Por outro lado, além de trazer para o primeiro plano este aspecto prático, "realista", de dois dos principais autores liberais brasileiros, também atribuía fortes componentes utópicos à pretensão, recorrente nos autores conservadores, de fazer do Estado, ou de uma suposta "razão abstrata", o princípio ordenador da sociedade. Num livro de sugestivo título, Medo à utopia (1985), dedicado ao pensamento social de Tobias Barreto e Sílvio Romero, Moraes Filho assinala que, "em nome da ciência", Barreto e Romero "tiveram medo de ser utópicos", isto é, "não assumiram um compromisso de uma nova sociedade com o futuro" (Moraes Filho, 1985: 279) - raciocínio, aliás, que também estende a Oliveira Vianna. Assinala ainda que, "na verdade, é impossível fazer parar o tempo, [...] apelando para a pura razão e para o puro raciocínio lógico como o caminho do entendimento e da manutenção do status quo, somente com pequenas e superficiais alterações" (Moraes Filho, 1985: 37). Por esse motivo, as pretensões de Vianna de controlar o dinamismo social através de uma excessiva centralização estatal também seria utópica. Pergunta-se, nesse sentido, Moraes Filho a respeito das posições políticas do autor de Populações:

Seria, ou deverá ser indicada essa terapêutica, em detrimento das forças vivas da sociedade? Não seria substituir a tirania dos antigos chefes localistas e demagógicos por outra ainda pior, por que única e infalível? (...) Em verdade, o seu idealismo também foi utópico, metido o país numa camisa-de-força, bem próxima da ficção - neste século, já tão verdadeira! - de George Orwell (Moraes Filho, 2003: 344-345).

Em síntese, se para Oliveira Vianna a tese do "insolidarismo", o prognóstico autoritário e a rejeição do liberalismo seriam diferentes momentos de um único raciocínio - formando um "sistema" -, o debate travado por Moraes Filho, que aqui se reconstruiu brevemente, coloca em suspenso, ou pelo menos torna mais contingente, cada uma dessas passagens. Afinal, como visto na seção anterior, a centralização excessiva poderia agravar, em vez de corrigir, o "insolidarismo"; no mesmo passo, a rejeição dos autores liberais não levaria necessariamente a uma visão mais "realista" dos problemas do país, podendo, pelo contrário, reforçar o descompasso entre o Estado e a dinâmica da vida coletiva, já que ela sempre escaparia às pretensões demasiado ordeiras de dominá-la. 
Se o processo de construção do Estado-nação não se faz desacompanhado de narrativas que conferem orientação, sentido e motivação aos seus portadores, constitui sempre um desafio analisar sociologicamente o modo pelo qual as ideias finalmente se transformam em "forças sociais", em componentes decisivos desse mesmo processo que buscam descrever. Ao tratar aqui destes dois intelectuais statemakers, que produziram ao mesmo tempo formulações clássicas sobre a sociedade brasileira e projetos de intervenção do Estado sobre ela, parte deste mistério pode ser elucidada, especialmente se recuperamos em uma chave não-disjuntiva estes dois momentos. Além disso, foi justamente ao buscar os nexos entre a atividade intelectual de Vianna e Moraes Filho e suas atuações no MTIC que foi possível reuni-los sob uma mesma perspectiva cognitiva, porquanto ambos articulam, num mesmo movimento, a dimensão social e a institucional (que, em geral, andam separadas), em que pesem as suas muitas diferenças, exploradas brevemente neste texto.

Talvez, a questão mais premente não seja saber por que tal ou qual intelectual aderiu ao processo de state-making, mas indagar, invertendo-se a questão, por que a sociedade brasileira cobra reiteradamente, ainda que com sentidos distintos ao longo do tempo, o protagonismo de seus homens de ideias (Bastos, 2006).

\section{Notas}

1. Para uma análise mais detida deste livro, ver Gomes (2005) e Villas Bôas (2005).

2. Para uma análise desta questão e seus desdobramentos em autores posteriores, ver Botelho (2007).

3. Para uma análise da práxis corporativa de Vianna, ver Gomes (1993).

4. Para esta questão, ver Brasil Jr. (2007), especialmente o terceiro capítulo.
5. Cf. Howes (1975) e Brasil Jr. (2007).

6. Para uma análise deste livro, em perspectiva comparativa com Raizes do Brasil, de Sérgio Buarque de Holanda, ver Gomes (1990).

7. Cf. a longa entrevista concedida recentemente pelo autor e reunida em livro (Morel et. al., 2007). 
BASTOS, Elide Rugai. Paulo Augusto de Figueiredo e o pensamento autoritário no Brasil. In: — RIDENTI, Marcelo \& ROLLAND, Denis (orgs.). Intelectuais e Estado. Belo Horizonte: Ed. UFMG, 2006.

BOTELHO, André. O Brasil e os dias. Estado-nação, modernismo e rotina intelectual. Bauru, SP: EDUSC, 2005.

CANDIDO, Antonio. O significado de Raizes do Brasil. In: HOLANDA, Sérgio Buarque de. Raizes do Brasil; org. Ricardo Benzaquen de Araújo, Lilia Moritz Schwarcz, ed. rev. São Paulo: Companhia das Letras, 2006 (edição comemorativa de 70 anos).

GOMES, Angela M. C.. O problema do sindicato único no Brasil: um livro faz 50 anos. In: PESSANHA, Elina; VILLAS BÔAS, Glaucia \& MOREL, Regina (orgs.). Evaristo de Moraes Filho: um intelectual humanista. Rio de Janeiro: Academia Brasileira de Letras, Topbooks, 2005.

A dialética da tradição. Revista Brasileira de Ciências Sociais. São Paulo, $\mathrm{n}^{\circ}$. 12, v. 5, 1990, p. 15-27.

A práxis corporativa de Oliveira Vianna. In: BASTOS, Elide Rugai \& MORAES, João Quartim de (orgs.). $O$ pensamento de Oliveira Vianna. Campinas: Ed. Unicamp, 1993.

HOWES, Robert. W. Progressive conservatism in Brazil: Oliveira Viana, Roberto Simonsen and the social legislation of the Vargas regime, 19301945. Tese (Doutorado em História). Cambridge University, Grã-Bretanha, 1975.

MICELI, Sergio. Intelectuais e classes dirigentes no Brasil. In: - Intelectuais à brasileira. São Paulo: Companhia das Letras, 2001.

MORAES FILHO, Evaristo. Anteprojeto de Código do Trabalho. Rio de Janeiro: s/e, 1963.
O problema do sindicato único no Brasil: seus fundamentos sociologicos. $2^{\mathrm{a}}$ ed. São Paulo: Alfa-Ômega, 1978 [1952, $1^{\text {a }}$ edição].

. Medo à utopia: o pensamento social de Tobias Barreto e Sílvio Romero. Rio de Janeiro: Nova Fronteira, 1985.

. Temas de liberalismo e federalismo no Brasil. Rio de Janeiro: Academia Brasileira de Letras, 1991.

As idéias fundamentais de Tavares Bastos. $2^{\mathrm{a}}$ ed. Rio de Janeiro: Topbooks, 2001. [1 $1^{\mathrm{a}}$ edição, 1978].

$$
\text { - Quinze ensaios. São Paulo: LTr, } 2003 .
$$

MOREL, Regina.; GOMES, Angela Castro \& PESSANHA, Elina. F. Evaristo de Moraes Filho: arquiteto da sociologia e do direito do trabalho no Brasil. São Paulo: LTr, 2007.

PÉCAUT, Daniel. Os intelectuais e a politica no Brasil: entre o povo e a nação. São Paulo: Ática, 1990.

VIANNA, Francisco José de Oliveira. Problemas de direito sindical. Rio de Janeiro: Max Limonad, 1943.

- Populações meridionais do Brasil (vol. 1). Rio de Janeiro: Nova Aguilar 2002 [1920, $1^{\text {a }}$ edição].

- Instituições políticas brasileiras. Brasília: Câmara dos Deputados, 1982 [1949, $1^{\text {a }}$ edição].

História social da economia capitalista no Brasil (volume I). Belo Horizonte: Itatiaia; Niterói, RJ: Eduff, 1987a.

História social da economia capitalista no Brasil (volume II). Belo Horizonte: Itatiaia; Niterói, RJ: Eduff, 1987b.

VILLAS BÔAS, Glaucia. O insolidarismo revisitado em $O$ problema do sindicato único no Brasil. In: PESSANHA, Elina; VILLAS BÔAS, Glaucia \& MOREL, Regina (orgs.). 
Evaristo de Moraes Filho: um intelectual humanista. Rio de Janeiro: Academia Brasileira de Letras, Topbooks, 2005.
WERNECK VIANNA, Luiz. Liberalismo e sindicato no Brasil. Belo Horizonte: Ed. UFMG, 1999.

\section{Resumo}

Neste artigo, procura-se analisar, em perspectiva comparada, os argumentos de Oliveira Vianna e Evaristo de Moraes Filho, dois intelectuais que se destacaram não apenas por suas reflexões sobre a sociedade brasileira, mas também por sua participação no Estado (no Ministério do Trabalho) e pela proposição de instrumentos jurídicos destinados à intervenção sobre a mesma. Pretende-se, ainda, analisar estes dois "momentos", a análise sociológica e a criação de dispositivos normativos, de maneira integrada, buscando conexões de sentido entre as suas atuações como statemakers e as suas perspectivas cognitivas.

Palavras-chave: pensamento social brasileiro; intelectuais; Estado-nação; Oliveira Vianna; Evaristo de Moraes Filho.

\section{Abstract}

This article aims to examine comparatively the arguments of Oliveira Vianna and Evaristo de Moraes Filho. Both analyzed the Brazilian society, but also participated in the state apparatus (in the Ministry of Labor), and created legal instruments to intervene on the society. I try to examine these two "moments", the sociological and the juridical one, in an integrated way, seeking the meaningful connections between their roles as statemakers and their cognitive perspectives.

Key words: Brazilian social thought; intellectuals; nation-state; Oliveira Vianna; Evaristo de Moraes Filho.

\section{Résumé}

Cet article vise à examiner, d'une façon comparative, les arguments de Oliveira Vianna et Evaristo de Moraes Filho. Les deux ont analisé la société brésilienne, mais aussi ont participé à l'appareil d'État (au ministère du Travail), où ils ont créé des instruments juridiques pour intervenir sur la société. J'essaie d'examiner ces deux «moments», le sociologique et le juridique, d'une manière intégrée, en cherchant les liens significatifs entre leurs rôles comme statemakers et leurs perspectives cognitives.

Mots-clés: pensée sociale brésilienne; intellectuels; État-nation; Oliveira Vianna; Evaristo de Moraes Filho. 